\title{
Conceptual Understanding of Screen Media Parenting: Report of a Working Group
}

\author{
Teresia M. O'Connor, MD, MPH,' Melanie Hingle, PhD, MPH, RD, Ru-Jye Chuang, MS,3 \\ Trish Gorely, $\mathrm{PhD}$, Trina Hinkley, $\mathrm{PhD}{ }^{5}$ Russell Jago, $\mathrm{PhD}{ }^{6}$, Jane Lanigan, $\mathrm{PhD},{ }^{7}$ \\ Natalie Pearson, $\mathrm{PhD}^{8}$, and Darcy A. Thompson, $\mathrm{MD}, \mathrm{MPH}^{9}$
}

\section{Abstract}

Screen media (television, computers, and videogames) use has been linked to multiple child outcomes, including obesity. Parents can be an important influence on children's screen use. There has been an increase in the number of instruments available to assess parenting in feeding and physical activity contexts, however few measures are available to assess parenting practices regarding children's screen media use. A working group of screen media and parenting researchers convened at the preconference workshop to the 2012 International Society for Behavioral Nutrition and Physical Activity (ISBNPA) annual meeting, "Parenting Measurement: Current Status and Consensus Reports," to identify and prioritize issues in assessing screen media parenting practices. The group identified that screen media use can pose different risks for children, depending on their age and developmental stage, across physiologic, psychosocial, and development outcomes. With that in mind, a conceptual framework of how parents may influence their child's screen-viewing behaviors was proposed to include the screen media content, context of viewing, and amount viewed. A research agenda was proposed to prioritize a validation of the framework and enhance the ability of researchers to best assess parenting influences across the three domains of content, context and amount of children's screen media use.

\section{Introduction}

O creen media use-defined as television viewing, computer/electronic game playing, or use of portable screen-based devices - is central to the lives of young people ${ }^{1-3}$ and is a dominant form of leisure time behaviors for many youth. ${ }^{4,5}$ Survey data suggest that screen media use begins at a very young age, ${ }^{6}$ and the amount of time children and adolescents spend with media is increasing. ${ }^{7}$

There are some benefits associated with screen media use, such as improved reading recognition, ${ }^{8}$ academic skills, ${ }^{9}$ and vocabulary and expressive language use ${ }^{10}$ among preschoolers who watched certain age-appropriate educational programs. However, there is accumulating evidence that exposure to certain types and amounts of screen media is associated with increased risk of multiple physiologic, psychosocial, and developmental problems, independent of physical inactivity. For example, high levels of television viewing have been associated with unfavorable physiologic outcomes such as unfavorable body composition, ${ }^{11-13}$ decreased fitness, ${ }^{14,15}$ high blood pressure, ${ }^{16,17}$ and increased risk of metabolic syndrome. ${ }^{18}$ Screen media use has also been

\footnotetext{
'Children's Nutrition Research Center, Department of Pediatrics, Baylor College of Medicine, Houston, TX.

${ }^{2}$ Department of Nutritional Sciences, College of Agriculture and Life Sciences, University of Arizona, Tucson, AZ.

${ }^{3}$ University of Texas Health Science Center, School of Public Health, Houston, TX.

${ }^{4}$ University of Stirling, Stirling, Stirlingshire, United Kingdom.

${ }^{5}$ Centre for Physical Activity and Nutrition Research (C-PAN), School of Exercise and Nutrition Sciences, Deakin University, Burwood, Victoria, Australia.

${ }^{6}$ Centre for Exercise, Nutrition and Health Sciences, School for Policy Studies, University of Bristol, Bristol, United Kingdom.

${ }^{7}$ Department of Human Development, Washington State University Vancouver, Vancouver, WA.

${ }^{8}$ School of Sport, Exercise, and Health Sciences, Loughborough University, Loughborough, Leicestershire, United Kingdom.

${ }^{9}$ Department of Pediatrics, University of Colorado, Aurora, CO.
} 
associated with adverse psychosocial outcomes such as problems with sleep, ${ }^{19}$ externalizing and aggressive behaviors, ${ }^{19}$ problematic interpersonal relationships, ${ }^{20}$ increased risk taking, ${ }^{21,22}$ and disordered eating. ${ }^{12,22}$ Excessive screen exposure at an early age has also been associated with adverse developmental outcomes, such as decreased reading recognition, comprehension, and short-term memory, ${ }^{8,19}$ problems with language and vocabulary development, ${ }^{9,10}$ and reduced school readiness. ${ }^{9}$

Of recent interest to many researchers, clinicians, and public health workers is the link between screen media use and child obesity. The majority of this work has examined the association between TV viewing and child obesity. ${ }^{15}$ Several theories have been proposed that could explain the association including TV viewing: (1) Displacing time that would be otherwise spent in physical activity (the "Couch Potato Hypothesis"), ${ }^{23-25}$ (2) promoting eating while viewing leading to higher energy consumption; ${ }^{12}$ (3) exposing children to food advertising which influences their dietary intake, ${ }^{26}$ (4) decreasing children's total sleep duration, ${ }^{27}$ which may alter their metabolic hormonal pathways related to hunger and appetite; and/or (5) having a reverse $^{28}$ or bidirectional ${ }^{29}$ effect in which obese children view greater amounts of TV than nonobese children. All of these mechanisms have at least some evidence to support them. For example, some studies found that physical activity decreases as screen time increases supporting the "couch potato effect," ${ }^{23-25}$ but this has not always been supported. ${ }^{30-32}$ Greater attention is now being focused on the influence that TV viewing has on children's dietary intake, with one longitudinal cohort ${ }^{29}$ and two randomized controlled TV reduction interventions ${ }^{3,33}$ finding that dietary intake, and not physical activity, mediated the effect of TV viewing on children's weight status. One study showed that viewing TV with advertisements, compared with advertisement-free TV, contributes to this pathway. ${ }^{26}$ In fact, the mechanisms are likely complex, multifactorial, and may differ by child age and other characteristics. Qualitative studies support that parents perceive TV viewing as influencing children's physical activity and dietary intake. ${ }^{34}$ Parent's perceptions of the mechanisms by which children's screen media use results in desired or undesired child outcomes may influence how they interact with their child regarding screen media use.

While mechanisms underpinning the associations of screen viewing with health outcomes have not been well delineated, young children who view high amounts of television tend to remain high television viewers relative to others over time. ${ }^{35}$ Many national organizations have recognized the potential problems associated with high levels of screen media use among youth and have published guidelines and implemented health promotion campaigns to reduce youth screentime. ${ }^{36-40}$

Screen media parenting practices refers to goal-directed parent behaviors or interactions with their child about media for the purpose of influencing some aspect of the youth's screen media use behaviors, e.g., restricting a child's time engaged in screen media use, or encouraging a child to view certain content. The American Academy of Pediatrics (AAP) recommends pediatricians promote screen media parenting practices that restrict children's use across three dimensions - amount, content, and context. ${ }^{40}$

Much of the preliminary work on screen media parenting practices comes from the field of communication science, where the focus has been on TV viewing (referred to as "parental mediation of TV viewing"). ${ }^{41-44}$ More recently, medical and public health literature have included assessments of parenting practices related to youth screen media use. The most commonly defined dimensions of media parenting practices include restrictive mediation (restricting the amount or content of screen media allowed), ${ }^{44} 46$ co-viewing (shared viewing with no intentional discussion), ${ }^{4-46}$ and instructive mediation (purposeful discussions parents initiate related to content). ${ }^{44,46}$ Recent work has proposed other dimensions that relate to the context of viewing (e.g., with meals) or control of child behavior (e.g., making screen use contingent on other behaviors) ${ }^{47,48}$ Survey data have shown that the majority of parents use at least one parenting practice to influence their child's screen media behavior. ${ }^{49}$

Measurement of screen media practices has been restricted by inconsistent assessment of parenting practices and limited reliability and validity data on existing measures. ${ }^{45}$ Past measurement has focused almost exclusively on television viewing and has not taken into consideration present day media use by youth or simultaneous use of multiple screens. ${ }^{45}$ In fact, screen media parenting is unique compared to parenting in other contexts, because technologies that deliver media continue to rapidly advance, making it difficult for researchers (and parents) to keep pace.

To advance our understanding of the role parents play in influencing children's media use and ultimately children's health, there is a need to further define the construct of screen media parenting practices and its dimensions. Consideration must be given to the broader literature on domain-specific parenting practices (e.g., feeding and physical activity) and the defined parenting dimensions in other domains. These assessments should include parents' perceptions of outcomes, because their attitudes and beliefs will likely influence their screen-viewing parenting practices. Additional research also needs to define the mechanisms that link screen media use with both desired and adverse outcomes. Finally, systematic assessment of the validity and reliability of the resulting screen media parenting measures and assessment procedures are needed to ensure that the theoretically defined constructs and related dimensions are appropriately assessed in future observational, experimental, and intervention studies.

\section{Screen Media Parenting Working Group}

A working group of 11 screen media and parenting researchers met to identify and prioritize issues in assessing 


\section{Table I. Screen Media Domains: Context, Content, and Amount}

\begin{tabular}{l|l} 
Screen media domain & \multicolumn{1}{c}{ Definition } \\
Content & $\begin{array}{l}\text { The message delivered from the media that youth view or interact with, which can be further categorized into: } \\
\text { - purpose (e.g., educational or entertainment) } \\
\text { - programming content (e.g., age-appropriate or not, such as content with portrayal of sexual behaviors, } \\
\text { violence, drug use, profanity) } \\
\text { - commercial versus noncommercial (e.g., with or without advertisement) }\end{array}$ \\
\hline Context & $\begin{array}{l}\text { Circumstance in which the viewing occurs including: } \\
\text { - who is present with the child } \\
\text { - the location it is taking place (e.g., living room, bedroom, on-the-go, at school) } \\
\text { - when it is occurring (such as time of the day, daylight/non-daylight) } \\
\text { - how it is delivered (i.e., television, DVD, computer, tablets, or handheld gaming consoles) } \\
\text { - whether screen media use occurs in relation to other activities (e.g., while eating or doing homework) }\end{array}$ \\
\hline $\begin{array}{l}\text { Frequency and duration that youth are engaged in screen media use, including: } \\
\text { - how much of each media type is used } \\
\text { - how often it is used (i.e., unique episodes or continuous), } \\
\text { - whether or not use occurs simultaneously with other screen media (i.e., multitasking) }\end{array}$ \\
\hline Amount ("dose")
\end{tabular}

screen media parenting practices during the preconference to the 2012 International Society for Behavioral Nutrition and Physical Activity (ISBNPA) meeting "Parenting Measurement: Current Status and Consensus Reports." 50 The group developed a conceptual framework for how screen media parenting practices may influence the content, context, and amount of children's screen media use (see Table 1 for definitions); discussed how the published constructs of media parenting practices may influence one or more of these screen media use domains; ${ }^{45}$ and identified additional parenting practice constructs that warrant further study. By investigating parenting practices across the dimensions of amount, content, and context of screen use by their child, research may be able to better delineate how parents influence children's outcomes (e.g., obesity) via several of the proposed pathways. The working group also outlined a suggested research agenda to further refine the screen media parenting practice conceptual framework.

\section{Parenting Practices within the Domains of Content, Context, and Amount}

Instruments assessing screen media parenting focusing on medical and public health child outcomes have recently been reviewed ${ }^{45}$ with multiple parenting practice constructs identified (Table 2). In addition, the broadcast and communication literature has identified the practice of instructive mediation. ${ }^{4,46}$ Monitoring has also been identified as a practice used by parents to restrict or be aware of the screen media a child uses. ${ }^{51-53}$ Due to the limited number of studies investigating screen media use and associated parenting practices and the lack of valid and reliable screen media scales that assess a range of media parenting practices, it is likely that there remain multiple important parenting practices that do not yet appear in the medical or public health literature. The working group proposed six new parenting practice dimensions that are likely to relate to young people's screen media use (Table 2).
Each of the parenting practices identified in the literature and by the working group may encourage or discourage children's screen media use related in part to the content, context, or amount of screen media use. For instance, co-viewing may influence the amount of screen media use if parents and children spend their time together consuming screen media. Co-viewing may also influence the content of screen media if parents display certain preferences or place restrictions on content viewed with their child; finally, co-viewing may influence context of the screen media use, if the child is only permitted to view screen media when the parent is available for co-viewing. Each of the parenting practices is defined in Table 2 and linked with each of the child viewing constructs - content, context, and amount- to which they may relate in Table 3 .

\section{Linking Screen Media Parenting Practices to Parenting in Other Domains}

The proposed framework was grounded in the developmental literature and parenting theory to maximize application to parenting practices across the spectrum of child health behaviors (e.g., food parenting practices, physical activity parenting practices, etc.). Because research regarding parenting influences on children's screen media use is still at a very early stage, ${ }^{45}$ this conceptual framework is designed to be flexible to accommodate future changes based on accumulating empirical evidence. Previous work in other parenting contexts has identified control and responsiveness as important parenting dimensions that influence children's behaviors in general, ${ }^{54,55}$ as well as within feeding contexts. ${ }^{56}$ There are several existing screen media parenting practices (Table 2) that relate to the control (e.g., total timing and content restrictions) and responsiveness (e.g., co-viewing and encouragement of screen media) dimensions of screen media parenting practices. 
Table 2. Existing and Proposed Screen Media Parenting Practice Constructs

\begin{tabular}{|c|c|c|}
\hline $\begin{array}{l}\text { Screen Media Parenting } \\
\text { Practice construct }\end{array}$ & Proposed definition & $\begin{array}{l}\text { Existing or } \\
\text { proposed construct }\end{array}$ \\
\hline Total limits & $\begin{array}{l}\text { Parents have limits on the total amount of time the child can engage in screen } \\
\text { media use. }\end{array}$ & Existing ${ }^{45}$ \\
\hline Timing limits & $\begin{array}{l}\text { Limits to screen media use are implemented by parents based on the time of day } \\
\text { (e.g., no screen media use an hour before bed). }\end{array}$ & Existing ${ }^{45}$ \\
\hline Content restrictions & Parents have restrictions on the content of screen media allowed. & Existing ${ }^{45}$ \\
\hline Contingent viewing & $\begin{array}{l}\text { Screen media time is dependent upon something else (e.g., completing } \\
\text { homework or taking nap). }\end{array}$ & Existing ${ }^{45}$ \\
\hline Parental supervision & $\begin{array}{l}\text { Parents supervise screen media behaviors by being in the same room, but not } \\
\text { necessarily co-viewing. }\end{array}$ & Existing $^{45}$ \\
\hline Co-viewing & Parents watch television together with their child. & Existing ${ }^{45}$ \\
\hline Encouragement of TV & $\begin{array}{l}\text { Parents encourage child viewing of TV that may be specific to certain types of } \\
\text { programming or certain times. }\end{array}$ & Existing ${ }^{45}$ \\
\hline Instruction & $\begin{array}{l}\text { Parents provide instructions regarding what is viewed on screen media (explain } \\
\text { what characters are doing, the meaning of advertisements, etc.). }\end{array}$ & Existing ${ }^{44,46}$ \\
\hline Providing choice & $\begin{array}{l}\text { Parents provide the child with choices regarding screen media use (such as } \\
\text { programing and timing). }\end{array}$ & Proposed \\
\hline Negotiated rules & Parents and child negotiate rules about screen media use allowed for the child. & Proposed \\
\hline Mealtime rules & There are rules about screen media use during mealtimes. & Existing $^{45}$ \\
\hline Monitoring & $\begin{array}{l}\text { Parents keep track at regular intervals of content, context or amount of screen } \\
\text { media used by child. }\end{array}$ & Existing ${ }^{51-53}$ \\
\hline Limits on co-activities & $\begin{array}{l}\text { There are rules on other activities that can be done while using screen media } \\
\text { (such as eating or doing homework). }\end{array}$ & Proposed \\
\hline Limits on location & $\begin{array}{l}\text { There are limits on where in the house screen media can be used (no TV in } \\
\text { bedroom, no handheld videogames in bedroom). }\end{array}$ & Proposed \\
\hline $\begin{array}{l}\text { Parent decisions that affect } \\
\text { availability }\end{array}$ & $\begin{array}{l}\text { Whether to have screen media equipment within the home environment; } \\
\text { extreme end is no screen media, or no TV in home. }\end{array}$ & Proposed \\
\hline $\begin{array}{l}\text { Parent decisions that affect } \\
\text { accessibility }\end{array}$ & $\begin{array}{l}\text { Whether to have screen media equipment in the home that is within sight of } \\
\text { child and easily accessed by child. }\end{array}$ & Proposed \\
\hline
\end{tabular}

Existing, Media parenting practices identified in Jago's et al. 2013 systematic review ${ }^{45}$ and the literature; proposed, media parenting practices identified by the Media Parenting Working Group in Houston.

An additional parenting domain of structure has been proposed to include ways that parents proactively organize a child's environment to support desired behaviors with consistent guidelines, expectations, and monitoring of child behaviors. ${ }^{56-58}$ Several of the proposed parenting constructs could be considered practices that structure the screen media environment in which children are raised (e.g., availability and accessibility of screen media, mealtime rules, and limits on locations and co-activities). Further research is needed to assess whether screen media parenting practice domains should be categorized according to existing parenting dimensions and assess whether other dimensions, such as autonomy supportive parenting practices ${ }^{59}$ (e.g., instruction, providing choice, and negotiated rules) may also have an important role in influencing children's screen media use.

\section{Recommendations for Screen Media Parenting Practices Scale Development}

This research group proposed that parents modify their parenting practices according to the type of screen media in which their child is engaged. This suggests that scales for different types of screen media use should be developed. Furthermore, screen media parenting practices may differ between school days and non-school days and should be assessed using this distinction. Formative studies are needed to identify the multiple ways in which parents interact with their child to achieve the same goal (e.g., limiting screen time). These data can be used to develop multi-item scales to assess each screen media parenting practice dimension. The discrete parenting practices identified by such research can populate a screen media parenting practice item bank and form the basis for 
Table 3. Matrix Framework of Media Parenting Practices and Which Relevant Screen Media Area They Are Likely to Influence

\begin{tabular}{|c|c|c|c|}
\hline & \multicolumn{3}{|c|}{ Screen media use-areas of focus } \\
\hline & Content of screen media & $\begin{array}{c}\text { Context that screens } \\
\text { are viewed }\end{array}$ & Amount or dose \\
\hline \multicolumn{4}{|l|}{ Media parenting practices } \\
\hline Total limits & $x$ & & $x$ \\
\hline Timing limits & & $x$ & $\mathrm{x}$ \\
\hline Content restrictions & $x$ & $x$ & \\
\hline Contingent viewing & $x$ & $x$ & $x$ \\
\hline Parental supervision & $x$ & $x$ & $x$ \\
\hline Co-viewing & $x$ & $x$ & $x$ \\
\hline Encouragement of TV & $x$ & $x$ & $x$ \\
\hline Instruction & $x$ & & \\
\hline Providing choice & $x$ & $x$ & $x$ \\
\hline Negotiated rules & $x$ & $x$ & $x$ \\
\hline Mealtime rules & & $x$ & $x$ \\
\hline Monitoring & $x$ & $x$ & $x$ \\
\hline Limits on Co-activities: & & $x$ & $x$ \\
\hline Limits on location & & $x$ & \\
\hline Parent decisions that affect availability & & $x$ & $x$ \\
\hline Parent decisions that affect accessibility & & $x$ & $x$ \\
\hline
\end{tabular}

developmentally appropriate, comprehensive assessments of the influence of different screen media parenting practices on children's screen media behaviors. To maximize the availability and accessibility of the proposed item bank to researchers, items and subscales designed to assess media parenting practices and general measures of parenting should be placed in public and highly accessible locations, e.g., as part of the Measures Registry, hosted by the National Collaborative on Childhood Obesity Research. ${ }^{60}$ This or similar locations will facilitate searches for appropriate instruments and facilitate their use by the child health and development research community.

With a screen media parenting practice framework proposed, consideration should also be given to how the proposed dimensions are best measured and which assessment procedures should be employed. In the fields of feeding ${ }^{61}$ and physical activity, ${ }^{62}$ parenting practices have traditionally been assessed by parent self-report or child report of parent behaviors. Self-report procedures are easiest to use in large observational or intervention studies. Therefore, the development of reliable and valid multiitem scales to assess screen media parenting practices would greatly advance this field. However, scientists should also be aware that such scales can be prone to individual reporting bias, as seen by low agreement between parent and child reports of parenting. ${ }^{63}$ This suggests that future research also needs to consider novel methods for assessing screen media parenting practices, such as virtual reality parenting simulations, implicit parenting attitude measures, or newer methods of self-report such as ecological momentary assessment or computerized adaptive testing methods. All of these are discussed in more detail by Mâsse et al. in this special issue. ${ }^{64}$

\section{Recommended Research Agenda}

The working group has proposed a conceptual framework informed by the current literature, in which parents influence their child(ren)'s screen media use across three different viewing/use domains - content, context, and amount. The framework could be applied across an aggregate of child screen media use types or each type separately, depending on the outcome(s) of interest. It is apparent that the field of screen media parenting is in an early stage and studies are needed to inform, refine, and expand the proposed conceptual framework. Such studies need to identify the individual parenting practices used within each existing or proposed parenting domain to develop screen media parenting practices scales and subscales. Additional work should explore whether there are 
additional or alternative ways parents attempt to modify their children's screen media use. The construct validity, internal consistency, external validity, reliability, and predictive validity of the resulting scales should be assessed to provide reliable, valid instruments for future research to assess the role of screen media parenting in children's health outcomes.

Once reliable and valid items and scales of screen media parenting practices have been developed, the proposed conceptual framework (Table 3) should be refined. Studies should assess each parenting practice domain's influence on children's content, context, and amount of screen media use, and whether the parenting practices differ by type of screen media used by children. The proposed influences are theoretical and based on face validity. The suggested associations need to be tested empirically, along with assessing additional or alternative associations. The proposed mechanisms by which screen media viewing effects certain child outcomes (e.g., obesity), likely involves other child behaviors, such as physical activity and dietary intake. Therefore, the influence of screen media parenting practices on these other (co-varying) behaviors should also be assessed to better understand the complex mechanisms by which screen media use effects outcomes. For example, restrictive TV parenting practices were associated with greater child sedentary time and less physical activity in one small study, ${ }^{65}$ suggesting that parenting in one domain may influence behaviors in another domain and these relationships may be complex and have bidirectional effects.

Media parenting may also be influenced by the number of children and developmental stage of each child in the home, the availability and location of various media in the home, parental beliefs and attitudes about screen media, and cultural norms. Measurements of parenting practices should be sensitive to differences in parenting relative to children's development. ${ }^{66}$ Media use varies by age, ${ }^{7}$ and parents may have different expectations based on their child's developmental stage, ${ }^{67}$ and the impact of the content viewed by the child will also vary by age and development. Finally, most of the existing parenting measures were developed using a singular cultural group (most often European American), ${ }^{68}$ and these measures may not apply to other groups of parents.

To effectively draw links between screen media parenting practices and child behaviors and outcomes, scientists also need to develop better methods for assessing child screen-viewing behaviors. Substantial problems and limitations have been identified in the current available measures of screen media use, ${ }^{69,70}$ which have focused on TV viewing. The most commonly used measure, child selfreport or parent proxy-report to estimate the minutes of TV viewing in a typical day, had low correlation (0.27) with home video observations. ${ }^{71}$ The current gold standard method to measure children's TV viewing, direct or videorecorded observation, ${ }^{71,72}$ is too expensive and intrusive for most field studies, may cause privacy concerns for participants, ${ }^{73}$ and requires additional costs of coding the video recordings at a later time, thus limiting its use in larger studies. TV diaries had higher correlations with home video recording $(r=0.84)$ than parent estimates, ${ }^{71}$ but are burdensome and require documentation of child activity every 15 minutes for several days, ${ }^{71,74,75}$ which may introduce systematic errors. Other methods, such as the TV Allowance ${ }^{\circledR}$ have not been validated compared to the gold standard, ${ }^{71,72,76}$ and require the child or parent to enter a child-specific code each time the child watches TV. This may cause misclassification errors if the child is not watching the entire time the TV is turned on or watches under another family member's code. However, this device is now discontinued and the authors are aware of no other similar devices available. These measurement problems reduce the likelihood of "high quality [screen media] exposure assessment" 69 and limit our ability to accurately measure screen media use, and tease apart the mechanisms by which screen media use is associated with child outcomes. Inaccurate measurement of screen media use creates substantial problems in fully characterizing the extent of children's screen media use behaviors or the impact that parenting practices can have on these behaviors.

\section{Conclusion}

The proposed screen media parenting practice conceptual framework offers a way to overcome many of the limitations of existing instruments ${ }^{45}$ and provides a comprehensive, coordinated, and systematic approach to assess screen media parenting. The framework and item bank will allow researchers to identify the parenting concepts that may be the most relevant to their research question, allowing them to develop a tailored assessment tool using age- and culturally appropriate items contained within the bank. In addition to supporting expansion of measurement to multiple health behaviors and outcomes, additional advantages of a common item bank include a reduction in redundant efforts to develop reliable and valid instruments to assess parenting practices (i.e., limiting "reinvention of the wheel"), and will facilitate comparisons across populations and systematic reviews of the parenting and child health literature.

\section{Acknowledgments}

We would like to thank the additional members who participated in the screen media working group at the preconference to the 2012 International Society for Behavioral Nutrition and Physical Activity (ISBNPA) annual meeting, "Parenting Measurement: Current Status and Consensus Reports": Holly Wethington, PhD (CDC), and Amy van Grieken, MSc (Erasmus MC University Medical Center).

This publication was made possible due to funding from several agencies. The preconference to the 2012 International Society for Behavioral Nutrition and Physical Activity (ISBNPA) annual meeting, "Parenting Measurement: Current 
Status and Consensus Reports" and resulting manuscripts were made possible due to funding from the United States Department of Agriculture/Agricultural Research Service (USDA/ARS 2012-68001-19285) and the National Heart, Lung, and Blood Institute of the National Institutes of Health (R13HL114262).

This report is also research arising from work supported by the United States Department of Agriculture/ Agricultural Research Service (USDA/ARS), Children's Nutrition Research Center, Department of Pediatrics, Baylor College of Medicine, Houston, Texas, and funded in part with federal funds from the USDA/ARS under Cooperative Agreement no. 6520-51000-053 (T. O'Connor); a Career Development Fellowship supported by the National Institute for Health Research, UK (R. Jago); and a Career Development Grant (5K23HD060666) from the Eunice Kennedy Shriver National Institute of Child Health and Human Development from the National Institutes of Health (D.A. Thompson). The views expressed in this publication are those of the authors and the contents of this publication do not necessarily reflect the views or policies of the funding agencies, nor does mention of trade names, commercial products, or organizations imply endorsement from any of the funding agencies or governments.

\section{Author Disclosure Statement}

No competing financial interests exist.

All of the authors participated in the screen media parenting working group at the preconference to the 2012 International Society for Behavioral Nutrition and Physical Activity (ISBNPA) annual meeting, "Parenting Measurement: Current Status and Consensus Reports." T. O'Connor led the working group and M. Hingle took notes during the working group that were shared with all participants. All the authors contributed written sections to the manuscript, critically reviewed and edited the final version, and approved the final submitted manuscript.

\section{References}

1. Marshall SJ, Gorely T, Biddle SJ. A descriptive epidemiology of screen-based media use in youth: A review and critique. $J$ Adolescence 2006;29:333-349.

2. Olds T, Ridley K, Dollman J. Screenie-boppers and extreme screenies: The place of screen time in the time budgets of 10-13 year-old Australian children. Aust N Z J Public Health 2006;30: 137-142.

3. Robinson TN. Reducing children's television viewing to prevent obesity: A randomized controlled trial. JAMA 1999;282:15611567.

4. Jago R, Page A, Froberg K, et al. Screen-viewing and the home TV environment: The European Youth Heart Study. Prev Med 2008; 47:525-529.

5. Anderson SE, Economos CD, Must A. Active play and screen time in US children aged 4 to 11 years in relation to sociodemographic and weight status characteristics: A nationally representative crosssectional analysis. BMC Public Health 2008;8:366.

6. Vandewater EA, Rideout VJ, Wartella EA, et al. Digital childhood: Electronic media and technology use among infants, toddlers, and preschoolers. Pediatrics 2007;119:e1006-e1015.

7. Rideout V, Foeher U, Roberts D. Generation M2: Media in the Lives of 8-18 Year Olds. The Henry J. Kaiser Family Foundation: Menlo Park, CA, 2010

8. Zimmerman FJ, Christakis DA. Children's television viewing and cognitive outcomes: A longitudinal analysis of national data. Arch Pediatr Adolesc Med 2005;159:619-625.

9. Wright JC, Huston AC, Murphy KC, et al. The relations of early television viewing to school readiness and vocabulary of children from low-income families: The early windows project. Child Dev 2001;72:1347-1366.

10. Linebarger DL, Walker D. Infants' and toddlers' television viewing and language outcomes. Ann Behav Sci 2005;48:624-645.

11. Hancox RJ, Milne BJ, Poulton R. Association between child and adolescent television viewing and adult health: A longitudinal birth cohort study. Lancet 2004;364:257-262.

12. Pearson N, Biddle S. Sedentary behaviour and dietary intake in children, adolescents and adults: A systematic review. Am J Prev Med 2011;41:178-188.

13. Marshall SJ, Biddle SJH, Gorely T, et al. Relationships between media use, body fatness and physical activity in children and youth: A meta-analysis. Int J Obes Relat Metab Disord 2004; 28:1238-1246.

14. Chinapaw MJM, Proper KI, Brug J, et al. Relationship between young peoples' sedentary behaviour and biomedical health indicators: A systematic review of prospective studies. Obes Rev 2011;12:e621-e632.

15. Tremblay MS, LeBlanc AG, Kho ME, et al. Systematic review of sedentary behaviour and health indicators in school-aged children and youth. Int J Behav Nutr Phys Act 2011;8:98.

16. Martinez-Gomez D, Tucker J, Heelan K, et al. The association of sedentary behaviors and blood pressure in young children. Arch Pediatr Adolesc Med 2009;163:724-730.

17. Tremblay M, Colley R, Saunders T, et al. Physiological and health implications of a sedentary lifestyle. Appl Physiol Nutr Metab 2010;35:725-740.

18. Sanders MR, Woolley ML. The relationship between maternal self-efficacy and parenting practices: Implications for parent training. Child Care Health Dev 2005;31:65-73.

19. Mistry KM, Minkovitz CS, Strobino DM, et al. Children's television exposure and behavioural and social outcomes at 5.5 years: Does timing of exposure matter? Pediatrics 2007;120: 762-769.

20. Jolin EM, Weller RA. Television viewing and its impact on childhood behaviors Curr Psychiatry Rep 2011;13:122-128.

21. Kennedy CM. Television and young Hispanic children's health behaviours. Pediatr Nurs 2000;26:283-294.

22. Strasburger VC, Jordan AB, Donnerstein E. Health effects of media on children and adolescents. Pediatrics 2010;125:756-767.

23. Sisson SB, Broyles ST, Baker BL, et al. Screen time, physical activity, and over-weight in US youth: National Survey of Children's Health 2003. J Adolesc Health 2010;47:309-311.

24. Nelson MC, Neumark-Sztainer D, Hannan PJ, et al. Longitudinal and secular trends in physical activity and sedentary behavior during adolescence. Pediatrics 2006;118:e1627-e1634.

25. Hardy LL, Bass SL, Booth ML. Changes in sedentary behavior among adolescent girls: A 2.5-year prospective cohort study. $J$ Adolesc Health 2007;40:158-165. 
26. Zimmerman FJ, Bell JF. Associations of television content type and obesity in children. Am J Public Health 2010;100:334-340.

27. Arora T, Hussain S, Hubert Lam KB, et al. Exploring the complex pathways among specific types of technology, self-reported sleep duration and body mass index in UK adolescents. Int $J$ Obes (Lond) 2013 Jan 8; Epub ahead of print.

28. Pulsford RM, Stamatakis E, Britton AR, et al. Sitting behavior and obesity: Evidence from the Whitehall II study. Am J Prev Med 2013;44:132-138.

29. Fuller-Tyszkiewicz M, Skouteris H, Hardy LL, et al. The associations between TV viewing, food intake, and BMI. A prospective analysis of data from the longitudinal study of Australian children. Appetite 2012;59:945-948.

30. Burdette HL, Whitaker RC. A national study of neighborhood safety, outdoor play, television viewing, and obesity in preschool children. Pediatrics 2005;116:657-662.

31. Taveras EM, Field AE, Berkey CS, et al. Longitudinal relationship between television viewing and leisure-time physical activity during adolescence. Pediatrics 2007;119:e314-e325.

32. Melkevik O, Torsheim T, Iannotti RJ, et al. Is spending time in screen-based sedentary behaviors associated with less physical activity: A cross national investigation. Int J Behav Nutr Phys Act 2010;7:46.

33. Epstein LH, Roemmich JN, Robinson JL, et al. A randomized trial of the effects of reducing television viewing and computer use on body mass index in young children. Arch Pediatr Adolesc Med 2008;162:239-245.

34. del Rio Rodriguez B, Hilmers A, O'Connor T. Hispanic parents of overweight and obese children and their outcome expectations for children's TV viewing: A qualitative study. J Nutr Educ Behav 2013; in press.

35. Biddle SJ, Pearson N, Ross GM, et al. Tracking of sedentary behaviours of young people: A systematic review. Prev Med 2010;51:345-351.

36. Tremblay MS, Leblanc AG, Janssen I, et al. Canadian sedentary behaviour guidelines for children and youth. Appl Physiol Nutr Metab 2011;36:59-64.

37. Department of Health. Start active, stay active: A report on physical activity from the four home countries' chief medical officers. United Kingdom. 2011.

38. Department of Health. Change 4 life. Available at www.nhs.uk/ change4life/Pages/Default.aspx Last accessed June 19, 2013.

39. Department of Health and Aging. Australia's physical activity recommendations for 5-12 year olds. 2004.

40. American Academy of Pediatrics, Committee on Public Education. American Academy of Pediatrics: Children, adolescents, and television. Pediatrics 2001;107:423-426.

41. Collins WA, Sobol BL, Westby S. Effects of adult commentary on children's comprehension and inferences about a televised aggressive portrayal. Child Dev 1981;52:158-163.

42. Dorr A, Kovaric P, Doubleday C. Parent-child coviewing of television. J Broadcast Electr Media 1989;33:33-51.

43. Desmond RJ, Singer JL, Singer DG, et al. Family mediation patterns and television viewing: Young children's use and grasp of the medium. Hum Commun Res 1985;11:480.

44. Valkenburg PM, Krcmar M, Peeters AL, et al. Developing a scale to assess three styles of television mediation: "instructive mediation," "restrictive mediation," and "social coviewing." J Broadcast Electr Media 1999;43:52-66.

45. Jago R, Edwards MJ, Urbanski CR, et al. General and specific approaches to media parenting: A systematic review of current measures, associations with screen-viewing, and measurement implications. Child Obes 2013;9(S1):S-51-S-72.

46. Nathanson AI. Mediation of children's television viewing: Working toward conceptual clarity and common understanding. Communication Yearbook 2001;25:151.

47. Hardy LL, Baur LA, Garnett SP, et al. Family and home correlates of television viewing in 12-13 year old adolescents: The Nepean study. Int J Behav Nutr Phys Act 2006;3:24.

48. Salmon J, Timperio A, Telford A, et al. Association of family environment with children's television viewing and with low level of physical activity. Obes Res 2005;13:1939-1951.

49. Rideout V, Venderwater E, Wartella E. Zero to six: Electronic media in the lives of infants, toddlers, and preschoolers. Henry $\mathrm{J}$. Kaiser Family Foundation: Menlo Park, CA, 2003, pp. 1-35.

50. Baranowski T, O'Connor T, Hughes S, et al. Houston...We have a problem! Measurement of parenting. Child Obes 2013;9(S1): S-1-S-4.

51. Funk J, Brouwer J, Curtiss K, et al. Parents of preschoolers: Expert media recommendations and ratings knowledge, media-effects beliefs, and monitoring practices. Pediatrics 2009;123:981-988.

52. Larios SE, Ayala GX, Arredondo EM, et al. Development and validation of a scale to measure Latino parenting strategies related to children's obesigenic behaviors. The parenting strategies for eating and activity scale (PEAS). Appetite 2009;52:166-172.

53. Padilla-Walker LM, Coyne SM. "Turn that thing off!" Parent and adolescent predictors of proactive media monitoring. $J$ Adolescence 2011;34:705-715.

54. Baumrind D. Patterns of parental authority and adolescent autonomy. New Dir Child Adolesc Dev 2005:61-69.

55. Maccoby E, Martin J. Socialization in the context of the family: Parent-child interaction handbook of child psychology. In: Mussen PH (ed), Handbook of Child Psychology. Wiley: New York, New York, 1983, pp. 1-101.

56. Hughes SO, O'Connor TM, Power TG. Parenting and children's eating patterns: Examining control in a broader context. Int J Child Adolesc Health 2008;1:323-330.

57. Slater MA, Power TG. Multidimensional assessment of parenting in single-parent families. In: Vincent JP, ed. Advances in Family Intervention, Assessment and Theory. JAI Press: Greenwich, CN, 1987, pp. 197-228.

58. Grolnick W, Pomerantz E. Issues and challenges in studying parental control: Toward a new conceptualization. Child Dev Perspect 2009;3:165-170

59. Grolnick W, Kurowski C, Gurland S. Family processes and the development of children's self regulation. Educ Psychol 1999;34:3-14.

60. National Collaborative on Childhood Obesity Research (NCCOR). Measures registry. Available at http://tools.nccor.org/measures Last accessed June 12, 2013.

61. Faith MS, Scanlon KS, Birch LL, et al. Parent-child feeding strategies and their relationships to child eating and weight status. Obes Res 2004;12:1711-1722.

62. Sleddens E, Kremers S, Hughes S, et al. Physical activity parenting: A systematic review of questionnaires and their association with child activity levels. Obes Rev 2012;13:1015-1033.

63. Tein J, Roosa M, Michaels M. Agreement between parent and child reports on parental behaviors. J Marriage Fam 1994;56:341-355.

64. Mâsse LC, Watts AW. Stimulating innovations in the measurement of parenting constructs. Child Obes 2013;9(S1):S-5-S-13.

65. O'Connor TM, Chen TA, Baranowski J, et al. Physical activity and screen-media related parenting practices have different associa- 
tions with children's objectively measured physical activity. Child Obes 2013; in press.

66. Mowder BA, Shamah R, Taoxin Z. Current measures for assessing parenting of young children. J Early Childhood \& Infant Psychology 2010;6:115.

67. Centers for Disease Control and Prevention (CDC). Child development positive parenting tips. Available at www.cdc.gov/ncbddd/ childdevelopment/positiveparenting/index.html Last accessed June 12, 2013.

68. Lansford JE, Bornstein MH. Parenting attributions and attitudes in diverse cultural contexts: Introduction to the special issue. Parent Sci Prac 2011;11:87-101.

69. Atkin A, Gorely T, Clemens S, et al. Methods of measurement in epidemiology: Sedentary behavior. Int J Epidemiol 2012;41:14601471.

70. Hardy L, Hills A, Timperio A, et al. A hitchhiker's guide to assessing sedentary behavior among young people; deciding what method to use. J Sci Med Sport 2013;16:28-35.

71. Anderson D, Field D, Collins P, et al. Estimates of young children's time with television: A methodological comparison of parent reports with time-laps video home observation. Child Dev 1985;56:1345-1357.

72. Bryant MJ, Lucove JC, Evenson KR, et al. Measurement of television viewing in children and adolescents: A systematic review. Obes Rev 2007;8:197-209.
73. Borzekowski D, Robinson T. Viewing the viewers: Ten video cases of children's television viewing behaviors. J Broadcast Electr Media 1999;43:506-528.

74. Vandewater EA, Shim MS, Caplovitz AG. Linking obesity and activity level with children's television and video game use. $J$ Adolesc 2004;27:71-85.

75. Cummings HM, Vandewater EA. Relation of adolescent video game play to time spent in other activities. Arch Pediatr Adolesc Med 2007;161:684-689.

76. Robinson JL, Winiewicz DD, Fuerch JH, et al. Relationship between parental estimate and an objective measure of child television watching. Int J Behav Nutr Phys Act 2006;3:43.

Address correspondence to: Teresia M. O'Connor, MD, MPH Assistant Professor of Pediatrics Children's Nutrition Research Center

Department of Pediatrics Baylor College of Medicine 1100 Bates Street Houston, TX 77030

E-mail: teresia@bcm.edu 